\title{
LA DIOSA DEMÉTER Y SUS MISTERIOS ELEUSINOS FUENTES E INTERPRETACIÓN
}

\author{
María Esther Conejo
}

\begin{abstract}
RESUMEN
Las diversas fuentes sobre la diosa Deméter y su culto en los Misterios de Eleusis, se pueden resumir en dos grandes grupos: el literario, que incluye autores griegos y latinos, y el arqueológico, de más reciente fecha; ambos se complementan para ofrecer una visión de ellos. Aunque el secreto riguroso que caracterizó a todos los misterios antiguos, en cuanto a su contenido más profundo, se mantuvo, es posible formarse una idea bastante real sobre el funcionamiento de los ritos en Eleusis y sus efectos sobre sus seguidores. La controversia de los que dan prioridad a un tipo de fuente u otro, en realidad contribuye a aclarar, poco a poco, el significado de estos misterios.
\end{abstract}

\begin{abstract}
The different sources about Demeter and the Eleusinian Mysteries, can be groupped in two branches: the literary ones, which include Greek and Latin authors, and arqueology, of more recent vintage; each of them complement the other to offer a vision of the Mysteries. Even though the strict secrecy which caracterized all the ancient mysteries was kept, it is possible to obtain a fairly good idea of the functioning of the rites in Eleusis as well as its efects in its followers. The controversial studies which give priority to one source or the other, in fact contribute to shed ligth, slowly but surely, on the meaning of these Mysteries.
\end{abstract}

Los Misterios Eleusinos ${ }^{1}$ han sido objeto de estudio y especulación desde tiempos inmemoriales. Ya en el siglo $\mathrm{V}$ antes de Cristo, el historiógrafo Heródoto comparaba a DEMÉTER -diosa en cuyo honor se celebraban los misterios- con la diosa ISIS, y tomaba a Egipto como su lugar de procedencia ${ }^{2}$. Desde Herodoto hasta nuestros días, son muchas las dudas que sobre la diosa y su culto se han aclarado, pero queda todavía mucho por dilucidar.

La fuente primaria más importante que ha preservado la tradición oral en relación con el tema es el Himno Homérico a Deméter, que data, en su forma escrita, del siglo VII a. de C. y recoge información de esa época así como de tiempos mucho más remotos. Existen, además, valiosas -aunque esporádicas- referencias al tópico en numerosos autores griegos y latinos tan diversos como Píndaro, Esquilo, Eurípides, Aristófanes, Aristóteles, Plutarco, Pausanias, 
Apolodoro, Apuleyo, Cicerón, Horacio y otros. Los aportes más recientes vienen de las últimas excavaciones efectuadas en Eleusis, en el sitio donde se erigieron sucesivamente -a través de dos mil años- los varios templos de Deméter ${ }^{3}$.

Deméter es conocida en la mitología griega como la diosa de la simiente, que gobierna los frutos de la tierra, especialmente el trigo.

Pero su figura dista de ser simplemente "agraria". Deméter, como diosa del grano, nutricia y madre, ha sido estudiada desde diversos puntos de vista.

Uno de los más recientes y significativos estudios es el de la psicología de profundidad, que considera a la diosa -junto con otras seis diosas griegas- como una poderosa fuerza o arquetipo dentro de la psiqué femenina, capaz de ayudar a una mujer a conocerse a sí misma y a interactuar con los seres que la rodean. Dice, al respecto, la analista jungiana Jean Shinoda: "Deméter es el arquetipo maternal. Representa el instinto maternal realizado a través de un embarazo, o a través de proveer alimento físico, psicológico o espiritual a otros. Este poderoso arquetipo puede dictar el curso que la vida de una mujer tomará; puede tener un impacto significativo en la vida de otros; pero también puede predisponer a una mujer a la depresión, si su necesidad de 'alimentar' es rechazada o contrariada" (Shinoda 1984) ${ }^{4}$. Se podrá ver en el transcurso de este estudio la concordancia con el mito.

El culto en su forma exotérica -decíamos- fue un culto agrario, con celebraciones correspondientes a la siembra y la recolección del grano. Aunque el origen y procedencia del culto de Deméter es incierto, se mencionan Egipto, Tesalia, Tracia y Creta, como posibles localidades desde donde llegó a Grecia. En la Hélade, el culto se inició en Eleusis, posiblemente en la Época Micénica, alrededor del siglo XV a. de C.

Nuestro conocimiento del mito parte del Himno Homérico a Deméter, que narra la leyenda de la diosa: Hades, dios griego de las regiones subterráneas -a donde van las almas después de morir- con el consentimiento de Zeus, dios del Olimpo y "padre" de dioses y hombres- raptó a Perséfone o Kore, hija de Deméter y Zeus y se la llevó a su reino en el mundo subterráneo, sin conocimiento de Deméter. La madre, desolada, dejó el Olimpo y recorrió toda la tierra en vana búsqueda de su hija; (durante su peregrinaje, la tierra dejó de dar sus frutos pues la diosa en su angustia no se ocupó de ello). Un día, la diosa llegó a Eleusis bajo la apariencia de una anciana y fue recibida por el rey Keleus. A su tiempo, la diosa se reveló como tal ante los Eleusinos, y éstos le construyeron el primer templo. Entre tanto Zeus, para persuadirla de volver al Olimpo, y sobre todo de permitir que la tierra volviera a producir, pues la humanidad se moría de hambre, le ordenó a Hades que devolviera a Kore a su madre siempre que ésta no hubiese probado comida. Pero Hades se aseguró de que la muchacha probase unas cuantas semillas de granada, con lo cual, aunque pudo volver a la superficie con su madre, quedó comprometida a volver a Hades por una parte del año. Deméter recobró así la felicidad e hizo que en toda la tierra brotaran hojas, flores y frutos. Seguidamente, la diosa reveló a cuatro ancianos justos de Eleusis: Keleos, Eumolpos, Diokles y Triptólemos, la forma de conducir sus ritos y les educó en todos sus misterios "terribles misterios, los cuales nadie puede en ninguna forma transgredir, ni curiosear, ni revelar, pues un profundo temor (respeto) de los dioses chequea su voz"5.

Las celebraciones históricas de los Misterios Eleusinos coinciden tanto con el mito como con las condiciones de clima de Grecia. Sin embargo, la interpretación tradicional del 
mito lo hacía corresponder -como otros mitos griegos- al ciclo de la vegetación, que desaparece en otoño y reaparece en primavera. Las dudas profundas de eruditos como Frazer y Nilsson 6 han logrado dilucidar que Kore y Deméter no son diosas de la vegetación en sentido amplio, sino espíritus del Grano, con lo cual los grandes misterios quedarían relacionados con el regreso de Kore en el otoño temprano, cuando los campos se vuelven poco a poco verdes otra vez, después de la sequía del verano. Los misterios menores se celebran en la primavera y preparan para la recolecta y subsecuente período de sequía del verano durante el cual Kore estará en el mundo subterráneo.

Fácilmente se interpreta, en su contenido exotérico, que los rituales de los misterios se relacionaban con la muerte y renacimiento de la naturaleza. En un sentido más profundo -que se trata de dilucidar en lo posible con ayuda de los hallazgos arqueológicos- se interpreta el ritual como una esperanza de inmortalidad para el hombre.

El culto no era abierto al público general sino sólo a aquéllos que se sometían voluntariamente a la iniciación en los rituales prescritos por la tradición. Ellos hacían promesa solemne de no divulgar los ritos secretos. Este silencio que se le imponía a los iniciados, para siempre, sobre las cosas vistas y escuchadas en la celebración, fue uno de los requisitos del culto que, hasta donde se sabe, se guardó celosamente hasta la extinción del culto, ya en tiempos del cristianismo. Existe información específica que indica que quien transgredía esta norma era castigado severamente. Un ejemplo del siglo IV a. de C. involucra al general ateniense Alcibíades, quien después de haber tomado vino con sus amigos, se atrevió a parodiar, dentro de su casa, algunos actos de la celebración; Plutarco ${ }^{7}$ da detalles sobre el caso e informa que Alcibíades fue condenado "in absentia", todas sus propiedades fueron confiscadas y se invitó a todos los sacerdotes y sacerdotisas del estado de Atenas a pronunciar maldiciones contra él. Todavía en el siglo II de nuestra era, la prohibición era tan fuerte que Pausanias, viajero e historiador griego, no sólo evitó explicaciones sobre ciertas costumbres relativas a los misterios, sino que inclusive se abstuvo de mencionar las construcciones que se veían en los recintos sagrados de Deméter en Eleusis y en Atenas, ofreciendo la siguiente excusa: "Un sueño me prohibió describir lo que está dentro de las paredes del santuario; y con seguridad es muy claro que los no iniciados no pueden -dentro de la ley-escuchar sobre aquello que no les es permitido mirar" 8 . Horacio, poeta lírico y satírico de la época de Augusto, asegura que no se atrevería a ir en el mismo barco con una persona que hubiera divulgado el secreto de los misterios, "no fuera que le tocara correr la misma suerte"

Del contenido de los misterios, evidentemente, la información es escasa; sin embargo, acoplando la fragmentaria evidencia literaria con los últimos descubrimientos de origen arqueológico, se ha podido intentar una reconstrucción parcial de los misterios. Para dar una idea de lo fragmentario de la información, he aquí unos ejemplos: Plutarco hace referencia, en uno de sus escritos, a la brillante luz en medio de la cual aparecía el hierofante cuando se abría el "anaktoron"10; tiene también una importante alusión a la alternancia de sentimientos y estados de ánimo que experimentaban los iniciados en el transcurso de la iniciación. Igualmente, una frase atribuida a Aristóteles, pareciera indicar que los iniciados no "aprendían" nada, sino que "pathein", experimentaban, sufrían 11.

Los trabajos de arqueología, llevados a cabo en Eleusis desde 1882 hasta el presente, han arrojado cierta luz sobre los contenidos de los misterios, y mucha sobre su importancia a 
juzgar por el interés que despertó en las figuras prominentes y artistas de Atenas en diversas épocas. Gradualmente se ha ido excavando toda el área del santuario, revelando fundaciones de los diversos edificios que formaron el complejo desde los períodos heládico y micénico, a través del geométrico, el de Pisístrato, Cimón, y Pericles, hasta las épocas helenística y romana.

Sin entrar en los complicados y minuciosos argumentos de los arqueólogos (Milonas 1974) y como se mencionó, uniendo lo arqueológico a las fuentes escritas y al trabajo minucioso de eruditos como Paul Foucart, se ha llegado a reconstruir, con bastante certeza, el calendario de las ceremonias y otros detalles. Se sabe, por ejemplo, que existían tres grados de iniciación:

1. Iniciación preliminar a los misterios menores.

2. Iniciación a los Misterios Mayores o TELETE.

3. EPOPTEIA o grado supremo de iniciación.

Los misterios menores se celebraban una vez al año a comienzos de la primavera, en el mes de las flores, en honor de Kore, con Deméter como invitada de honor; estos ritos de iniciación sirvieron de ejercicio preliminar tendiente a una completa purificación del candidato; preparaban a los participantes para el segundo grado o Telete, un año después, purificándolos y creando la actitud necesaria para la comunicación de los Grandes Misterios. Cada candidato, con la dirección de un Mistagogos y de un miembro de las dos familias dinásticas Eumolpida 0 Kerikes experimentaba una ceremonia individual de purificación y limpieza, bajo el ojo vigilante del Hierofante. Parte importante de las ceremonias eran el ayuno, sacrificios, aspersiones con agua y cantos de himnos.

Los misterios mayores también se celebraban una vez al año (cada cuatro años con especial esplendor) en Boedromion, el mes sagrado de los misterios. En cuanto a los aspirantes, no existía exclusión étnica, ni política, ni de género, ni de clase, pero sí linguística, pues los "bárbaros", es decir, los que no hablaban la lengua griega, estuvieron excluidos de los ritos. Antes de la celebración, mensajeros especiales eran enviados a las ciudades griegas proclamando una Tregua Sagrada de 55 días, e instándolas a enviar una delegación oficial con pequeñas porciones de las primeras frutas de la estación para la diosa. Se sabe de mensajeros que, con el pasar del tiempo, fueron enviados a Egipto, Siria, Antioquía y otros lugares fuera de Grecia (Milonas 1974: 244).

Gracias a las inscripciones encontradas en las excavaciones, se conocen los funcionarios que participaban en estas celebraciones. Eran de dos clases: 1) los organizadores, que eran los más importantes magistrados de la ciudad de Atenas ${ }^{12}$. 2) El cuerpo de Sacerdotes de Eleusis integrado por:

El Hierofante: Sumo Sacerdote, elegido de por vida, dentro de la familia dinástica de los Eumoplidas. Solo él, en el momento más solemne de la celebración, podía mostrar a los Iniciados "las cosas sagradas" (ta hiera), revelación que completaba la iniciación. Solo él podía entrar en el Anaktoron. Era el intérprete de las antiguas leyes no escritas que regían la celebración, y tenía la autoridad para negar la iniciación a quienes considerara indignos de recibirla. Su súbita aparición, bañado en brillante luz, en frente de las puertas abiertas del Anaktoron, llenaba a los iniciados de admiración y respeto. 
Las Hierofantidas: dos sacerdotisas, principales asistentes del Hierofante, también de la familia Eumoplida, ejercían, de por vida, y participaban en la iniciación.

Sacerdotisa de Deméter: también designada en forma vitalicia, era tan importante que a veces disputaba con el Hierofante el privilegio y el derecho de celebrar ciertos sacrificios. Desempeñaba el papel de Deméter y Kore en el drama sagrado que se representaba como parte de la iniciación.

Sacerdotisas Panageis: se les llamaba "las sagradas" y no tenían trato con personas del sexo opuesto. Su función es incierta pero es probable que les correspondiera llevar "las cosas sagradas" en la procesión de Eleusis a Atenas.

El Dadukos: segundo en importancia entre los celebrantes masculinos. De la familia de los Kerykes, su función era vitalicia y participaba en la celebración de los misterios, iniciación y sacrificios purificadores. Tenía un privilegio especial: solo él podía purificar a los manchados de sangre; sin embargo, no podía entrar en el Anaktoron.

El Hierokeryx: Heraldo de los Iniciados, de la familia de los Kerykes. Ordenaba el silencio que debía ser observado por los iniciados. Leía la proclamación (Milonas 1974: $229-33)^{13}$.

Los aspirantes a la iniciación, "hombres del saber y buenos ciudadanos", se preparaban para la gran experiencia bajo la dirección de sus mystagogos o guías místicos. Al iniciado se le llamaba Mystes, y la iniciación era individual. El Telete o ceremonia de los misterios se celebraba en el templo llamado Telesterion (del verbo griego teleo -hacer perfecto, terminar en forma perfecta).

La iniciación era la culminación de las celebraciones para los misterios, que duraban varios días; se conocen algunas de las actividades que se desarrollaban durante varios de los nueve días, como por ejemplo, una gran procesión en la que los objetos sagrados de Deméter se removían del Anaktoron y eran llevados a Atenas. Era encabezada por el Hierofante, el Colegio de Sacerdotes de Eleusis, y las Sacerdotisas, quienes llevaban los objetos sagrados en receptáculos sagrados (kistai), sellados, y por supuesto, nadie tenía oportunidad de ver el contenido. El cuerpo de sacerdotes atenienses y todo el pueblo los recibían y llevaban al Eleusinion -templo sagrado de Deméter en Atenas-. Los preliminares de los ritos, por consiguiente, se llevaban a cabo en Atenas y consistían en: la lectura, por parte del Hierokeryx, en presencia del Hierofante y el Dadukos, de la proclamación, invitando " a todo aquél que tenga las manos limpias y habla inteligible (griego), aquel que es puro de toda polución y cuyo espíritu no sabe de maldad, y aquel que ha vivido bien y justamente", a iniciarse en los ritos. El resto debía abstenerse.

Es curiosa, a este respecto, la anécdota que F. Philostrato ${ }^{14}$ cuenta sobre Apolonio de Tyana, a quien se le negó el derecho a participar, por ser considerado un hechicero o mago. No se sabe de otros requisitos o restricciones. El siguiente día, el llamado "Al mar, oh Iniciados" era la invitación a purificarse en el mar. "El Mar -dice Eurípides 15 - limpia y purifica al hombre de todo mal". También Esquilo16 considera al mar "inmaculado".

Había un día dedicado a Asclepios, dios restaurador de la salud. Aristóteles escuetamente manifiesta que este día los iniciados tenían que permanecer en el templo, pero no da razón alguna ${ }^{17}$ sobre el por qué. 
Una vez que la procesión regresaba a Eleusis con los aspirantes atenienses y las delegaciones de otros lugares de dentro y fuera de Grecia, ya de noche, a la luz de las antorchas, entraban en un amplio patio del santuario, dentro del Temenos.

Existen pinturas, sobre todo en cerámica, relacionadas con las dos diosas y con partes de las celebraciones. Un grabado, el llamado Tableta Niinion (Milonas 1974: 257), describe el resto de esa noche, que era dedicado a cantos y danzas en honor de Deméter y Persefone. También Aristófanes hace mención de estas actividades 18 .

El día de la iniciación, aparentemente se empleaba en descanso, ayuno, purificación y sacrificios. Los antiguos siempre creyeron que a través del ayuno se obtenía tanto una pureza de cuerpo y de espíritu, como una revigorización esperitual. Porfirio el Neoplatónico ${ }^{19}$ da informes sobre el ayuno de los iniciados a los cuales no se les permitía comer ciertas clases de pescado, aves domésticas, granadas, manzanas, carne de animales no muertos en la forma estipulada, huevos y vino. Hay también referencias a una cierta poción o potage especial que los iniciados tomaban -el kykeon-, en conexión con el ayuno pero solo podemos suponer que se tomaba al terminar el ayuno.

Sobre la Iniciación al Telete, hay muchas hipótesis; pero lo que sucedía en el santuario cerrado, los ritos principales, donde los misterios eran revelados, son hasta hoy desconocidos. Aún aquellos iniciados que ya a principios de nuestra era se convirtieron al cristianismo habiendo anteriormente recibido los Ritos Eleusinos, guardaron el voto del silencio. Sin embargo, se ha podido dilucidar (Milonas 1974: 261) que los ritos incluian tres elementos diferentes:

1) "Ta droómena": Lo que es representado -aunque no se sabe por quién (los sacerdotes, los mystai o ambos).

2) "Ta deiknúmena": Los objetos sagrados que eran revelados a los iniciados.

3) "Ta legómena": explicaciones y fórmulas ritualistas pronunciadas en el curso de la iniciación.

"Ta droómena" era un drama sagrado, posiblemente vinculado a la historia de Deméter y Perséfone, silencioso y con escasa explicación, en el cual cada gesto era una revelación. E. Schure (Schuré 1973: 225 ss) elaboró una reconstrucción del drama, dotándolo del contenido esotérico que debió de haber tenido y trató de hacer sentir al lector lo que el iniciado sentía en aquellos instantes. La reconstrucción es impresionante y conduciva a sentimientos sucesivos de reverencia, tristeza, desesperación y felicidad que podían -como en la tragedia griega- producir en el iniciado una catarsis o purificación. A estas alturas, ya vamos entendiendo la cita atribuída a Aristóteles ${ }^{20}$, en donde específicamente dice que los iniciados no iban a "aprender" nada, sino a "sufrir" -pathein- en el sentido de sentir o experimentar ciertas impresiones y estados de ánimo.

Entre los investigadores del tema, antiguos y modernos, algunos aseguran que parte de la iniciación consistía en un viaje simulado al Hades, que ponía a prueba toda la presencia de ánimo del candidato. Plutarco manifiesta a este respecto:

"El espíritu tiene la misma experiencia que aquellos que son iniciados a los grandes misterios (...) primero uno vaga y fatigosamente se apresura de un lado para otro, y viaja con recelos a través de las tinieblas como un no-iniciado; ento'nces vienen todos los terrores, antes 
de la iniciación final: escalofríos, temblor, transpiración, aturdimiento; de pronto uno es sacudido por una maravillosa luz, uno es recibido en las regiones y praderas puras con voces y danzas y la majestad de sonidos y formas santas. Aquél que ha cumplido la iniciación, discurre entre ellos libremente y liberado, y, llevando su corona se une a la comunión divina y se asocia con seres puros y divinos, contemplando a aquellos que viven aquí, no-iniciados, una horda impura, pisoteada, soportando sus miserias por miedo a la muerte y desconfianza de las bendiciones que trae." 21

El pasaje, no sólo interesante, sino muy sugestivo, ha encontrado defensores como P. Foucart (Foucart 1914), que trata de probar la hipótesis, y oponentes, entre ellos G. Milonas, quien critica a Foucart arguyendo 1) que el pasaje de Plutarco no aclara si los "grandes misterios" de que habla son los de Eleusis; 2) que éste habla indistintamente de la muerte y la iniciación sin que sea posible distinguir a cual se refiere, y 3) que el Himno Homérico a Deméter no menciona castigos para los no-iniciados; solo promete a los iniciados una vida más feliz después de la muerte, mientras que el pasaje de Plutarco habla en términos más que despectivos de los no-iniciados (Milonas 1974: 263-64).

Del segundo elemento de la iniciación, el "deiknúmena", la revelación, se conoce que el clímax de la celebración se alcanzaba cuando el Hierofante de pie, en frente del Anaktoron y en medio de una radiante luz (y aquí recordemos que no había iluminación eléctrica) exhibía los objetos sagrados -ta hierá- ante los iniciados. No se conoce ningún otro detalle ni el final de la iniciación.

Del tercer elemento, el "legómena", la parte hablada, no se sabe nada. Foucart se inclina a creer que incluía instrucción a los iniciados para ser empleada en el Hades, comparable talvez a la que se encuentra en el Libro de los Muertos de los egipcios.

La "epopteia" o tercer grado, parece haber sido una etapa especial, solo conferida a unos pocos. Constituía el más alto grado de los Misterios, y estaba restringida a aquellos, de entre los iniciados a los Misterios Mayores, que aspirasen a un grado mayor de entendimiento y perfección. Se sabe que algunas de las "cosas sagradas" eran reveladas únicamente a éstos pocos. Los ritos especiales de la "epopteia" se celebraban, posiblemente, durante la última noche en Eleusis, cuando el resto de los iniciados terminaban sus celebraciones y partían hacia sus hogares, dejando el templo a los pocos candidatos a la "epopteia". Si conocemos poco de los grados anteriores, en lo referente a los ritos de este grado estamos absolutamente a oscuras. Sin embargo, una investigación filológica de los términos griegos empleados, puede ayudar a sacar algunas conclusiones. El verbo epopteúoo posee varias acepciones: considerar, observar, vigilar, contemplar, estudiar. Todas, acepciones que apuntan hacia una actividad que implica atención o alertitud y que llevan hacia un fin cognoscitivo. El sustantivo epopteia tiene un significado muy claro y definido: CONTEMPLACIÓN. Pero, ¿cuál era el objeto de esta contemplación? La mayoría de los investigadores asocian esta contemplación con ta hierá, las cosas sagradas que eran reveladas a los epoptai; el problema es que generalmente las toman como "objetos" exclusivamente, todos relacionados con el culto agrario exotérico que Deméter representa. Es curioso que ninguno de tales investigadores -a excepción de Shuré- haya pensado en disociar estos dos aspectos de los misterios, tratando de encontrarle a la contemplación una solución diferente. Preferimos pensar, sobre la base de los dos términos, en una solución encaminada, más bien, hacia una contemplación de naturaleza interna, quizas mística, no precisamente de objetos, sino tal vez de verdades o leyes eternas. 
Se dice que los iniciados regresaban de su peregrinación a Eleusis llenos de regocijo y felicidad, con el miedo a la muerte disminuido y la esperanza fortalecida de una vida mejor después de ella. El mismo Himno Homérico a Deméter hace la promesa: "Feliz aquel de los mortales que ha visto esto; en el oscuro reino de las sombras, la suerte del iniciado y la del noiniciado, no es la misma" 22. Píndaro hace eco a estas palabras cuando escribe: "Feliz es aquel que, habiendo visto estos ritos, va debajo de la hueca tierra; porque él conoce el final de la vida y él conoce su comienzo enviado de dios." 23

La iniciación no obligaba a los iniciados en ninguna forma, excepto a guardar silencio sobre las cosas secretas vistas u oídas. Aparte de esto, podían regresar a su vida normal, enriquecidos por sus experiencias, que tal vez les ayudaban, como dice Diodoro ${ }^{24}$, a ser más "reverentes, más justos y mejores en todo".

La sustancia básica de los ritos secretos nunca fue revelada; el contenido se mantuvo intacto, transmitido oralmente, de hierofante a hierofante a través de las generaciones, por espacio de dos mil años; el secreto fue posiblemente enterrado con el último de sus hierofantes.

Lo único que resta por recapacitar es: ¿qué habrán significado los Misterios Eleusinos para los griegos? ¿Por qué Píndaro, Esquilo, Platón y tantas otras figuras prominentes del mundo helénico le habrán dado tanta importancia como para que hoy, dos milenios después, todavía podamos conocer de ellos a través de sus escritos? ¿Será acaso que los misterios contenían -como sugiere K. Seligman -"la semilla de la sabiduría entera"? (Seligman 1968: 96). Es posible que el culto de Eleusis haya satisfecho los más sinceros anhelos y las ansias más profundas del espíritu griego. No en vano nos dice Cicerón, el más grande orador de todos los tiempos -amante y conocedor de todo lo griego-: "Atenas no ha dado al mundo nada más excelente o divino que los Misterios Eleusinos"25.

\section{Notas}

1. El término "misterios", en su significado original, se refiere a cultos secretos que generalmente incluían ideas místicas; característica de los misterios es que, para ser admitido a ellos, se requería una iniciación. Entre los misterios griegos más antiguos, están los de Deméter y los de Dionysos. Ver Delcourt, M. 1947. Les Grands Santuaires de la Grece. Paris: Presses Universitaires de France.

2. Heródoto, Historias, II, 123 .

3. La fuente más completa y más reciente sobre arqueología es George Milonas. 1974. Eleusis and the Eleusinian Mysteries. New Jersey: Princeton University Press.

4. Shinoda Bolen, Jean. 1984. Goddesses in Every Woman. Harper \& Row, Publishers Inc. La traducción es mía.

5. Himno Homérico a Deméter, 478.

6. Nilsson, M., 1954. La Religión Popular en la Grecia Antigua. París. Además, Martin, R. y Metzeger, H. 1977. La Religión Griega. Madrid: EDAF.

7. Plutarco, Alcibíades, 19-22.

8. Pausanias, I, 38,7.

9. Horacio, Odas, III, 2, 25-29. 
10. Plutarco, de profect. virt., 81E.

11. Aristóteles, apud Synesius, Dion, p 48A.

12. Desde la conquista de Eleusis por parte de Atenas. Antes de eso toda la celebración se daba en Eleusis.

13. Consultar para una lista completa de los funcionarios y sus deberes en la iniciación.

14. Filostrato, F., Vit. Apol. IV,

15. Eurípides, Ifigenia en Tauride, 1193.

16. Esquilo, Los Persas, 577.

17. Aristóteles, Constitución de Atenas, LVI, 4.

18. Aristófanes, Las Ranas, 340-50.

19. Porfirio, De Abstin., IV, 16.

20. Ver nota 12 supra.

21. Plutarco, apud a Stobaios, 25. La traducción es mía.

22. Himno Homérico a Deméter, 480-83.

23. Píndaro, Fr. 102, Oxford. La traducción es mía.

24. Diodoro, V, 48.

25. Cicerón, De Legibus, 2, 14, 36.

\section{Bibliografía}

Delcourt, M. 1947. Les Grands Santuaires de la Gréce. Paris: Presses Universitaires de France.

Foucart, P. 1914. Les Mystères d' Eleusis. París.

Martin, R. y Metzeger, H. 1977. La religión griega. Madrid: EDAF.

Milonas, George. 1974. Eleusis and the Eleusinian Mysteries. New Jersey: Princeton University Press.

Nilsson, M. 1954. La religión popular en Grecia antigua. París.

Seligman, K. 1968. Magic, supernaturalism and religion. New York: Grosset \& Dunlap.

Shinoda Bolen, Jean. 1984. Goddesses in every woman. Harper \& Row, Publishers Inc.

Shuré, E. 1973. Orfeo, Pitágoras y Platón. Buenos Aires: Editorial Kier. 


$$
\text { - }
$$

$$
\text { (1) }
$$

